\title{
A Comprehensive Index to Evaluate Non-motorized Accessibility to Port-Cities
}

\author{
Nadia Giuffrida $^{1 *}$, Elena Cocuzza ${ }^{1}$, Matteo Ignaccolo $^{1}$, Giuseppe Inturri $^{2}$ \\ ${ }^{1}$ Department of Civil Engineering and Architecture, University of Catania, Via S. Sofia 64 - 95123 Catania, Italy \\ ${ }^{2}$ Department of Electrical, Electronic and Computer Engineering, University of Catania, Via S. Sofia 64 - 95123 Catania, Italy
}

Corresponding Author Email: nadia.giuffrida@ dica.unict.it

https://doi.org/10.18280/ijsdp.150516

Received: 6 January 2020

Accepted: 4 May 2020

Keywords:
walkability, accessibility, Geographic
$\begin{aligned} & \text { Information System, } \\ & \text { OpenStreetMap }\end{aligned}$

\begin{abstract}
Guaranteeing permeability between port and city areas is a complex issue since, in recent years, there have been deep changes, due to the evolution of maritime transport, traffic volumes and port infrastructures, which have profoundly influenced the port-city relationship. The recent growing of the cruise and yachting sectors, however, highlighted the huge possibilities of economic development related to these activities, especially in the areas of the cities located close the ports. In this light, it is essential to ensure good accessibility to the city from the port (and vice versa) and to ensure that urban routes within the areas close to the port offer visitors a pleasant experience, in terms of walkability and opportunities. In this paper a Walkability Comprehensive Index to evaluate the quality of facilities in proximity to port areas will be presented; the index will include evaluation concerning the accessibility of the facilities, their Level of Service and the Places of Interests for visitors entering the city from the port. The calculation of the index is based on a spatial analysis with data obtained through field surveys and by an open source approach. The methodology is applied to the case study of the Port of Catania, a coastal city located in the south of Italy. The comprehensive index provides with information on each arc of the road network, offering an aid for decision-makers in prioritizing intervention for the improvement of non-motorized infrastructure within the interface area between the port and the city.
\end{abstract}

\section{INTRODUCTION}

Historically, the ports are incorporated into densely populated urban areas with which they share spaces and infrastructures. This closeness usually generates some critical issues, including congestion and other transport externalities, due to the coexistence of different traffic flows, with negative repercussions, in terms of social, economic and environmental impact, also on the surrounding areas. The technological innovation in the port and maritime sector has been quite modest for many years until the advent of containerization, at the end of the 1950s, when there was a remarkable growth, culminating in the last decade. This required a larger infrastructure capacity and greater and specialized connections with the hinterland. The consequence was the relocation of heavy port activities away from the original nucleus, dismissing vast areas deemed obsolete or insufficient; in other cases, instead, the lack of available areas or the presence of environmental constraints have forced the ports to keep them close to urban centres, causing a difficult coexistence. Therefore, the relationships between the port system, urban system and territory are conditioned by a variety of correlated factors. In fact, in addition to the evolution of technological and transport processes, the decisions of the local actors, the governance strategies, the historical-cultural and morphological conditions of the sites had effects on the organization of the port areas and on their relationships with the surrounding territory.

Today ports are key links in the global logistics chain, able to offer innovative and competitive transport services, and can be considered the chance to implement new planning strategies at different scales. Since the 1960s, many port-cities dominate the urban planning sector, in terms of redevelopment, recovery and integration between areas with different land use. In recent decades, thanks to the phenomenon of the Waterfront Redevelopment and the regeneration of port areas, ports became a complex of functions and interactions with the city and the territory, sharing, in the interface areas, not only reception functions and transport activities, but also commercial, recreational, tourist, cultural and urban spaces. Such new port configuration attracts important flows of people, linked to the cruise, recreational boating and tourism sectors, so ports have to face new interactions between its areas and the city's ones. In this context, ports spaces that lost their previous commercial functions, acquired a great potential of transformation, taking hold on sectors such as the tourist and cultural reception and becoming a unique opportunity to redevelop highly degraded or marginal areas. The port-city interface areas therefore represent the opportunity for a sustainable development of port systems, reconciling both the needs of the city and the port, and making their coexistence possible. In this view the concept of accessibility can be considered a key factor for each of the three pillars of sustainability (economic growth, environmental quality and social equity) [1-3] and has a decisive role in the processes of port-city planning. Undoubtedly, the redevelopment of port and surrounding areas must pass through more sustainable scenarios in line with European Union policies [4]. 
Often, the unplanned distribution of heterogeneous functions and activities (resulting in overlapping and intersecting flows of freight, private vehicles and people) and the presence of mixed functions in the interface areas are the main criticalities for the most vulnerable users, i.e. the nonmotorized ones. Having a good non-motorized accessibility would be essential in order to have a direct and safe relationship with the city centre thanks to high quality pedestrian and cycling paths and areas, with a reduced interference with vehicular traffic; this would lead the port to achieve also a greater level of competitiveness in the recreational, tourism and cruise sectors. Following the recent transformations in many international port-cities and the symbolic value that many port areas have taken, the port-city integration has become very topical issue. Furthermore, the improvement of the non-motorized port accessibility, making the port areas main nodes of the networks of urban, regional and national levels, is among the EU goals by 2050, in order to promote sustainable mobility.

Allowing ships' passengers to access the city is essential to ensure that tourist lines generate an, albeit short, economic impact and not just a burden due to the environmental externalities produced by the ships' access to the port. Establishing a good connection between the port and the city, starting from the needs related to tourism, can be a trigger for new urban regeneration opportunities, with particular reference to port-city interface areas.

Based on these premises, the aim of this study is to focus attention on non-motorized mobility in port-city areas and to provide a methodological framework to evaluate the quality of non-motorized paths, both in terms of accessibility, geometric characteristics, and attractiveness of routes, in order to identify the best paths, main critical issues and possible measures of intervention. Even if the methodology is applicable to other context, a particular focus is put on port-cities, due to the fact that often, in the case of ports with mixed commercial and passengers, tourists and cruise traffic, intersections between pedestrian flows and vehicular traffic can generate accidents if a proper non-motorized infrastructure is not present

The methodology has been applied to the case study of the Port of Catania, located in a medium sized city in the south of Italy, and its relationship with the surrounding urban areas.

\section{STATE OF THE ART}

The attractiveness of walkable environments to pedestrians depends on the general built environment that affects pedestrians' choices of walking routes, and geometry of the pedestrian facility. Of course, a high accessibility to a destination, meaning that streets are well connected and provide shorter paths to a destination [5], can be considered one of the main components of the built environment that affect pedestrian activities. In its general definition, accessibility deals with the ease of reaching opportunities (e.g. activities and destinations, goods, services). There is a wide literature on the subject that provides many aspects of the accessibility in transport planning: Hansen [6] states that it refers to "the potential of opportunities for interaction", while it is "the ease with which any land-use activity can be reached from a location using a particular transport system" according to Dalvi and Martin [7] and it is seen as "the benefits provided by a transportation/land use system" according to Ben-Akiva and Lerman [8]. The application of the concept of accessibility to a port has significant potential in determining and explaining the operational, competitiveness and economic performance of port [9], therefore accessibility can be seen as a core component of port development. Moreover, accessibility directly affect port-city relationship; in the context of a port, it is possible to consider two type of accessibility:

people accessibility: citizens and tourists should have the possibility to access the port and the leisure or urban life related activities simply and comfortably;

freight accessibility: a competitive port is a node of an efficient transport network that allows easy and quick entrance-handle-departure of goods, so an adequate accessibility by road and rail must be ensured, as well as the connection with inland terminals.

An ideal situation for a port is to have a good accessibility both for people and for freight; generally, it should have a direct relationship with the city centre thanks to high quality pedestrian and cycling paths and areas, with a reduced interference with vehicular traffic, as well as good transit accessibility. At the same time, the port should ensure a high quality to its commercial and operational activities that require adequate transport infrastructures for vehicular traffic.

The accessibility measures are usually restricted to motorized modes, but a relevant work is the one by Iacono et al. [10] that explores the issues related to the development of accessibility measures for no-motorized modes and present a calculation of such measures for a small study area in South Minneapolis, using both distance and time impedance measures. Such measures should be included when evaluating the global quality of a pedestrian facility; however, it is also relevant the inclusion of elements as the geometry of the facilities that obviously affect the ability to access the port.

A well-known method for assessing the performance of urban environments for pedestrian/cycling mobility is the Pedestrian Environment Review System, PERS [11], set up by the British Transport Research Laboratory and applied as a control tool for the pedestrian mobility system in central London. The PERS is applied through the compilation of forms (comments and scores on a series of parameters), collecting data subsequently processed by Geographic Information System (GIS) software. It is a systematic process for evaluating the pedestrian environment, within an objective operational framework, and identifying those factors deemed of fundamental importance for pedestrians moving in public spaces. This method allows to carry out in a short time surveys of the state of art and verifications which represent an effective system for the evaluation of pedestrian performances, with a collection of coherent, clear and comparable data. However, this evaluation method could suffer from the experience and personal consideration of the auditor groups.

A method based on a mathematical approach is the Pedestrian Level Of Service (PLOS) developed in the Highway Capacity Manual [12]; the PLOS is a qualitative measure used to evaluate the quality of traffic service. It describes the operating conditions of a flow on a trunk road (street, sidewalk and possible bike path) and how they vary according to the flow. The study for the pedestrian flow is carried out in analogy to the vehicular one considering as quantitative measures the freedom to maintain the desired pedestrian speed and overtake other pedestrians.

However, the evaluation of a pedestrian path cannot be separated from the pleasantness of traveling along it and therefore from the presence of services and activities, but also 
the aesthetic appearance of streets and buildings considering, for example, well-maintained building frontages or presence or trees $[13,14]$; streets with higher density and a greater variety of destinations, tend to be chosen more often by pedestrians [5]. In this view, Ignaccolo and Caprì [1] presented a method for analysing and controlling pedestrianization scenarios in the historic centre of an Italian city, calculating a measure of utility for each possible pedestrian scenario. In a recent study D'Orso and Migliore [15] developed a method considering the main factors influencing the walkability of an urban area in order to establish the priorities for intervention and applied it to rail station surroundings in the city of Palermo (Italy).

In a previous study, the authors the authors developed an evaluation framework for establishing the quality of pedestrian facilities in port-city areas [16], including a measure of the PLOS and evaluating the Utility of different paths: starting from the results of this framework in this study an improved Walkability Comprehensive Index (WCI), including evaluation on the PLOS, the accessibility of routes and their attractiveness for pedestrians entering the city from the port, will be presented. Integrating such components to the standard LOS evaluation is essential since unlike goods, whose choice of route is dictated by the principle of generalized minimum cost, pedestrian mobility, especially in urban areas, does not need to favour a fast movement from an origin to a destination. Commonly, pedestrian's route choice depends, indeed, on the quality of the path and the attractiveness of existing activities and spaces along it.

Compared to the approaches previously developed by other scholars, the method developed by the authors allows to: (i) consider both the quality of infrastructure through Level of Service evaluation and the Accessibility to activities, without neglecting the attractiveness of the paths; (ii) assign different weights to each of the aforementioned criteria, including the possibility to involve port and city's stakeholders in the evaluation process; (iii) providing an aid to decision-makers in prioritizing the improvement of a specific non-motorized infrastructure within the interface area between the port and the city.

\section{CASE STUDY}

\subsection{Territorial framework}

Methodology has been applied to the case study of Catania, which is a medium-sized city of about 300.000 inhabitants located in the south of Italy; the city develops along the Sicilian Ionian coast for a length of about $9 \mathrm{~km}, 2$ of which are characterized by the presence of the port (Figure 1a). The relationship with the sea is unique and of great traditional, historical, cultural and environmental value: nevertheless, this relation has been the subject of a wide debate for several years, being Catania awaiting a new General Urban Development Plan and the proposal for a Port Regulatory Plan (PRP), presented by the Port Authority in 2004.

The Port of Catania is an international seaport that carries out multi-purpose commercial activities: dry and liquid bulks, general cargo, Ro-Ro, ferry, cruise, shipbuilding, fishing and pleasure boating. Thanks to its location and connection with the regional road and motorway network, with the airport and the intermodal Bicocca train station, in the last years, Containers, Ro-Ro and Ro-Pax ferries have had significant developments and, today, it plays a central role in the regional economic system; in particular, in 2018 the port handled 99.157 Ferry passengers and 123.985 cruise passengers, making it one of the main passenger ports in Sicily $[17,18]$.

The freight traffic is located in the south area of the port, in the commercial New Darsena dock (Figure 1b), for a total of $120.000 \mathrm{~m}^{2}$ with an increase of $70 \%$ of the current surface. The northern area, instead, is characterized by a mixed use of areas and infrastructures, due to the significant and continuous commercial growth of recent years. An important criticality that results is the interference both of vehicle (i.e. private and freight traffic) and pedestrian flows and the absence of dedicated spaces and reserved paths for pedestrian and bicycle mobility. In order to minimize the interferences with congested urban traffic, the access and exit of heavy vehicles is allowed through the Faro Biscari gate, located to the south and connected to a highway facility, and the Dusmet gate is dedicated for pedestrians and private vehicles (Figure 1a). However, at present, along the external perimeter of the port, as well as along the neighbouring streets, it is possible to highlight a shortage of exclusively reserved areas for pedestrian and cycling mobility. Despite several proposals for redevelopment over time, the conditions of marginality and degradation that characterize the portion between the Faro Biscari gate and Dusmet gate are remaining.

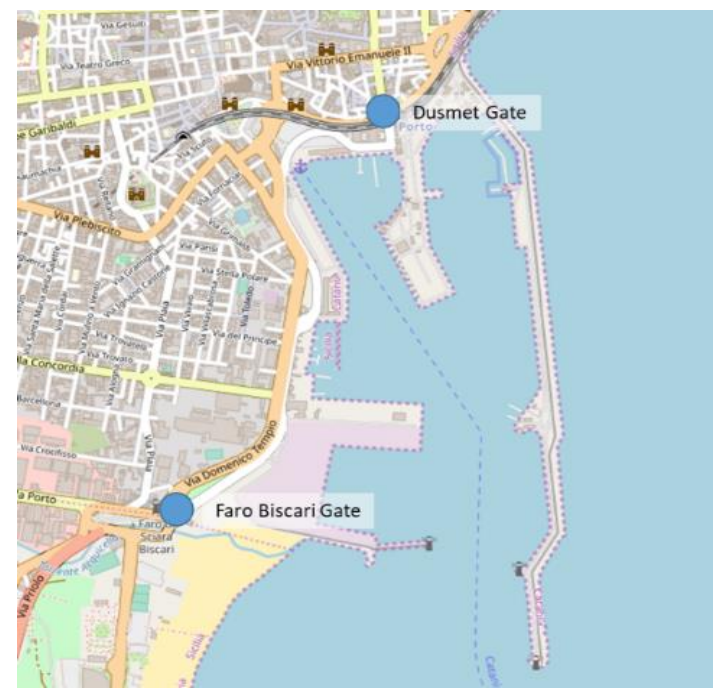

(a) Port of Catania gates location (Own elaboration from OpenStreetMap - OSM)

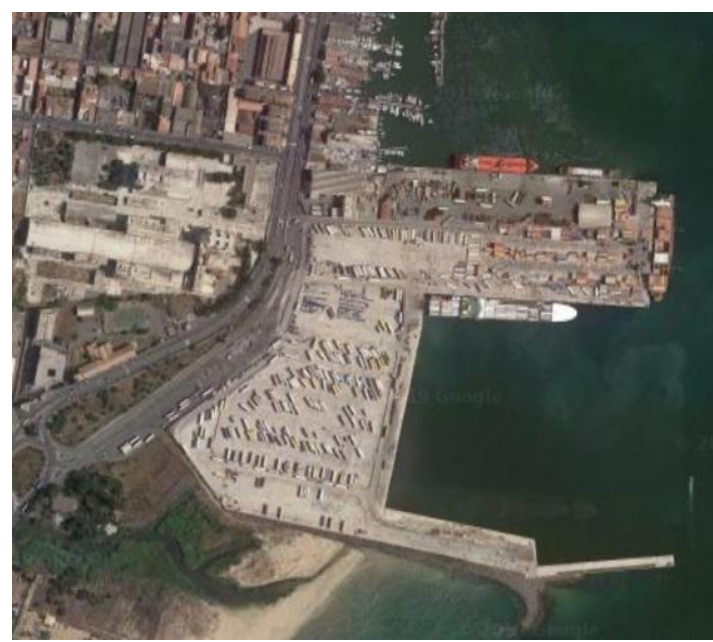

(b) Aerial view of New Darsena (Source: Google Maps)

Figure 1. Port of Catania 


\subsection{Software, data and analysed scenarios}

According to the literature review analysis, showing the need for a comprehensive approach to evaluate pedestrian quality of port-city shared areas, the formulation of a WCI aims at guaranteeing: (i) a good geometric layout and welldimensioned facilities that could guarantee pedestrian safety (which can be translated in a good PLOS); (ii) the possibility to access to different places of interest (Attractivity); (iii) a good accessibility in term of distance (Accessibility).

Based on this premise, the WCI will be developed according to an approach based on the following steps:

(1) Definition of the analysis area and design of the pedestrian network;

(2) Score evaluation for Level of Service, Attractiveness and Accessibility;

(3) Assignation of weights, calculation of the quality index and construction of a thematic map of intervention priorities.

3.2.1 Definition of the analysis area and design of the pedestrian network

The choice of an analysis area was made considering a walking distance of $1 \mathrm{~km}$ from the pedestrian entrance of the port (Dusmet gate); all the spatial procedures on the analysis area have been conducted through the use of QGIS, a GIS open source software providing with advanced spatial analysis tools for viewing and editing of geographic information. Through the plugin OpenLayers, QGIS allows to select a map as base layer for a project; in this study authors used the OSM standard map. The computation of the isodistance area has been performed through the plugin ORS Tools, a QGIS plugin which provides access to most of the functions of openrouteservice.org, based on OSM, and allowing to choose a "walking" mode in order to consider also pedestrian exclusive paths (e.g. public stairs or squares). The extension of the $1 \mathrm{~km}$ area was subsequently corrected based on the following considerations (Figure 2): (i) an spatial cut procedure has been performed in order to include only pedestrian port area in the analysis; (ii) the northern border of the analysis has been established to coincide with an arterial road delimitating the historic centre of the city; (iii) a final portion of the main pedestrian street of the city and one of the main squares have been included in the area even if it is located at a slightly farer distance $(200 \mathrm{~m})$.

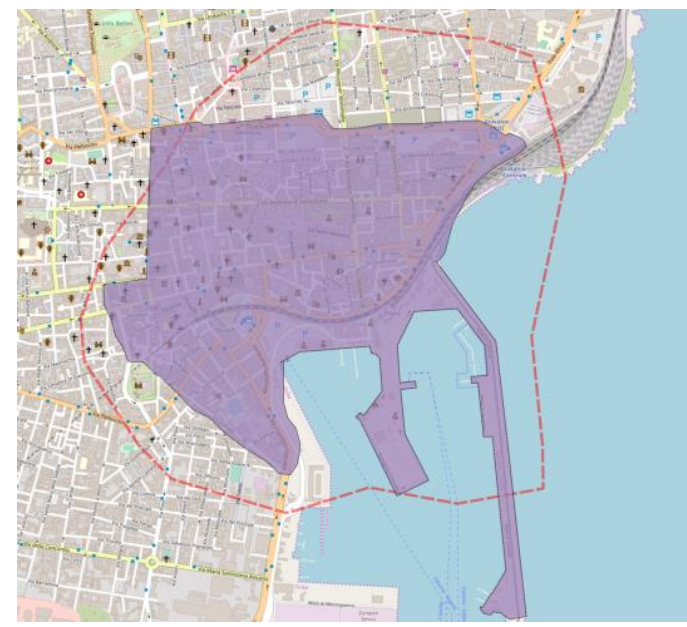

Figure $2.1 \mathrm{~km}$ area (red-dashed line) and final study area (fully in violet). Source: own elaboration
3.2.2 Attribution of scores for Level of Service, Accessibility and Attractiveness

For the evaluation of the three scores, normalized values (in the range $0-1$ ) of their indices have been considered.

The score attribution for Level of Service is based on the PLOS scores for segments calculated in a previous study [13] according to HCM2010 for a wider area, assuming a pedestrian travel speed of $3 \mathrm{ft} / \mathrm{s}$ and data on pedestrian and traffic flows from the General Urban Traffic Plan of Catania (2013). PLOS procedure is analogue to LOS for vehicular flow (with the aim to guarantee freedom of movement - move without interference and speed changes), but also considers some pedestrian experience factors (crowding, comfort, safety, environment, etc.). The facility is considered composed of segments, which are the made of intersections and links. A map of normalized scores for PLOS (PLOSn) in the study area is shown in Figure 3.

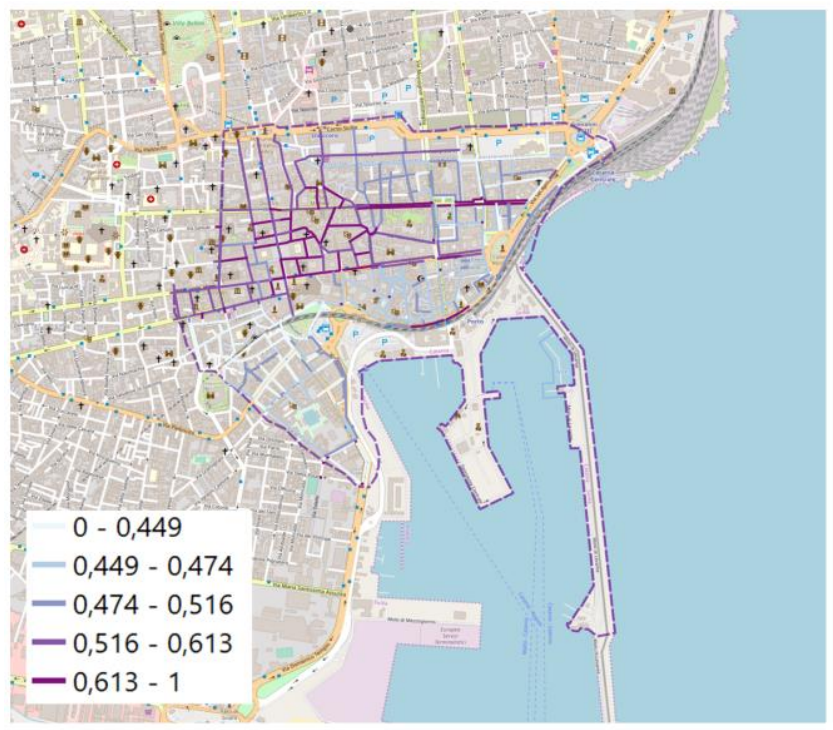

Figure 3. PLOSn score assigned to each arc. Source: own elaboration

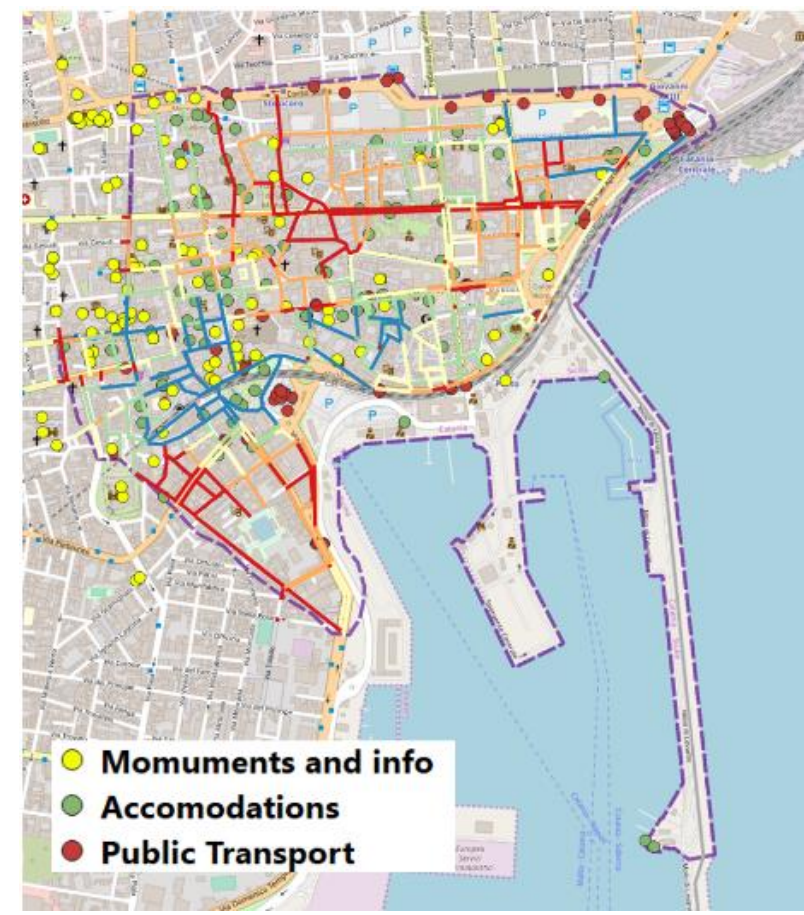

(a) POIn in the study area according to the three categories 


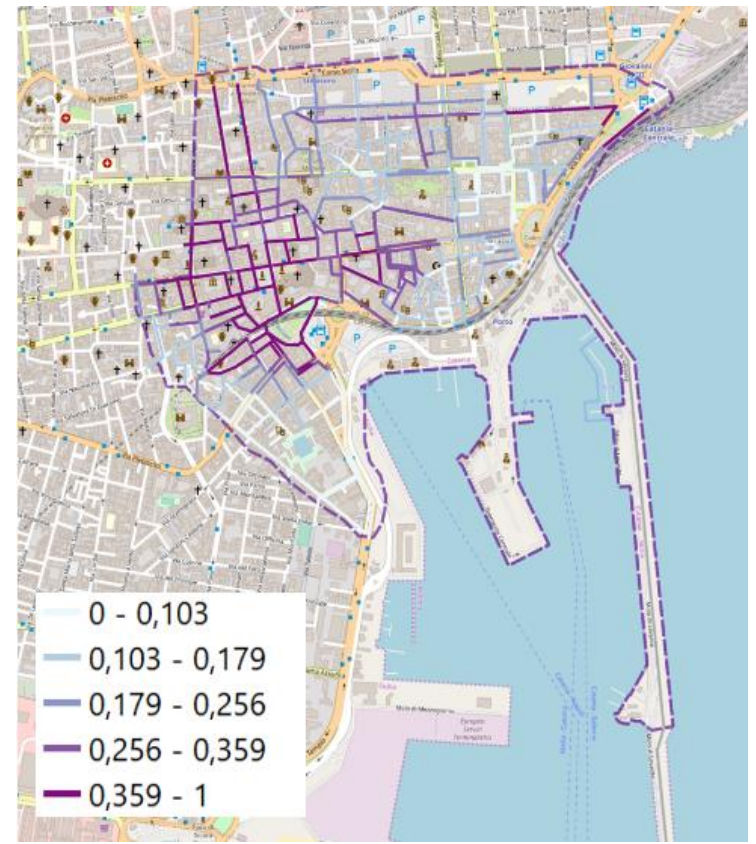

(b) Points of interest score assigned to each arc (normalized)

Figure 4. Attractiveness evaluation. Source: own elaboration

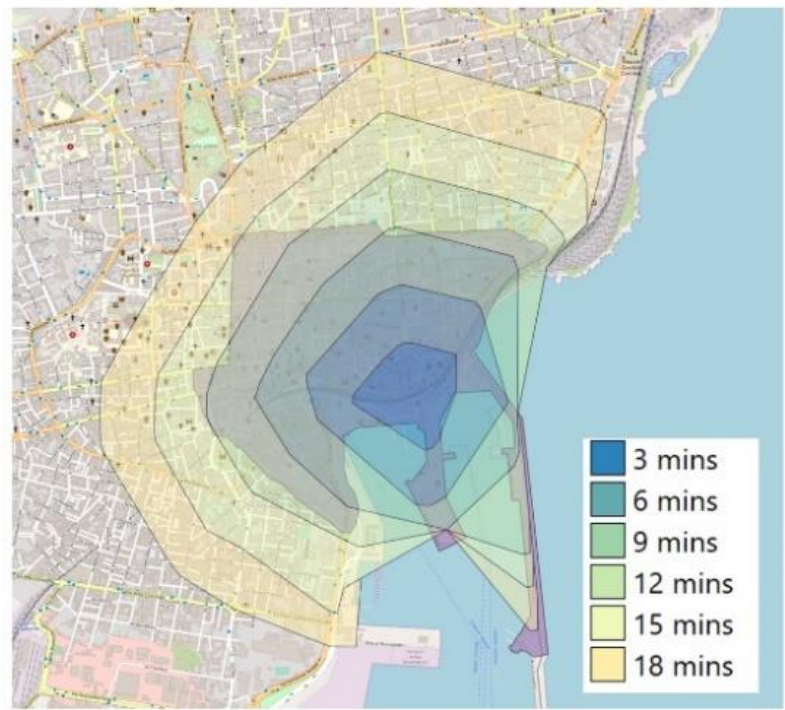

(a) Walking accessibility thresholds

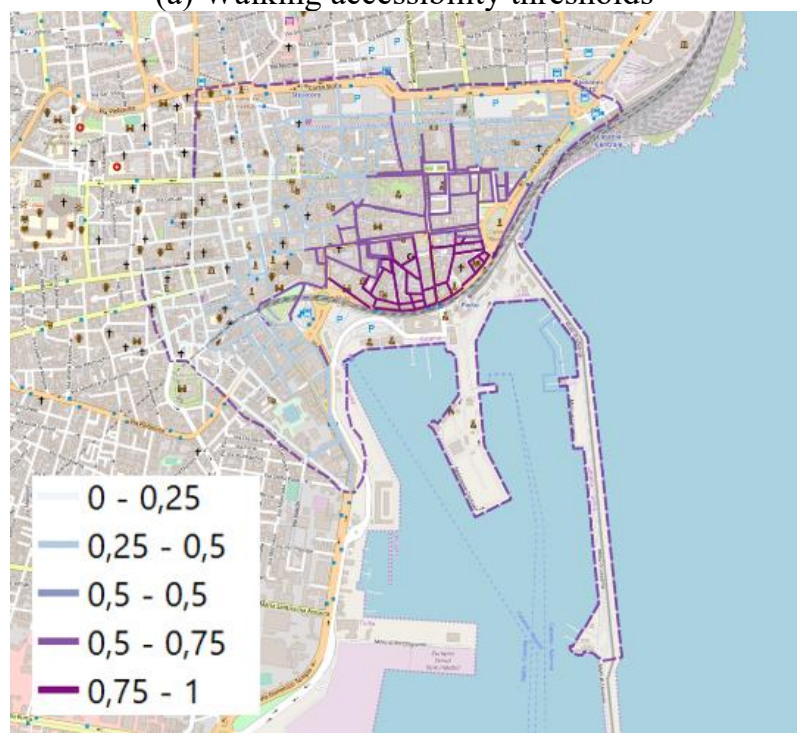

(b) $A_{n}$ score assigned to each arc

Figure 5. Accessibility evaluation. Source: own elaboration
The localization of Places of Interest (POI) has been conducted through the use of the plugin QuickOSM which queries OSM and extracts the requested data; three different categories of POI have been selected: Public Transport stops, Accommodation, Monuments and info points. Of course, the validity of such Open Source data, generally provided by volunteer users (such in the case of OSM), should be verified on the field [19]. Spatial analysis tools have been used to isolate the POI included in the study area and through an intersect operation values have been assigned to each arc, after their normalization (POIn) (Figure 4a and b).

The evaluation of walking-accessibility has been conducted by an impedance measure using six different time thresholds of 3 minutes. Isochrones have been computed by using the ORS plugin and the "walking" mode. Normalized accessibility score values (An) have been assigned to each arc through an intersect procedure (Figure $5 \mathrm{a}$ and $\mathrm{b}$ ).

3.2.3 Calculation of the quality index and construction of a thematic map

According to the literature review analysis, showing that the WCI for each arc i can be evaluated according to the following formula:

$$
\mathrm{WCI}=\beta 1 \mathrm{PLOSn}+\beta 2 \mathrm{POIn}+\beta 3 \mathrm{An}
$$

with $\beta 1, \beta 2$, and $\beta 3$ weight coefficient for each of the three components. In this study it has been decided to give the same weight to PLOSn and POIn (equal to 1) and to assign Accessibility a $\beta 3$ equal to 0,3 , to assign less importance to the distance of the locations, in comparison to the infrastructure quality of the facility and its attractiveness. This was done to consider that pedestrians would not mind walking longer distances to reach an attractive destination, if the path is pleasant and has a good infrastructure quality.

Based on the equation, the comprehensive index has been computed for each arc; a thematic map of results is shown in Figure 6.

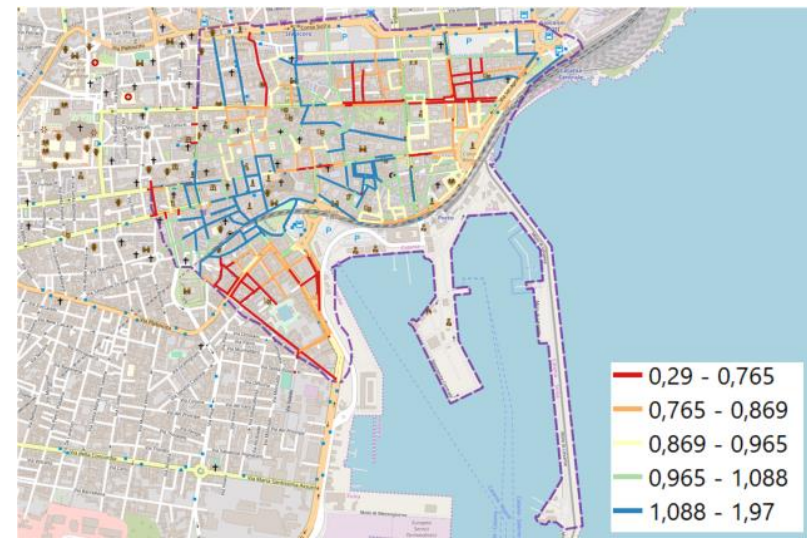

Figure 6. Map of WCI. Source: own elaboration

The most evident results that can be deduced from the thematic map are the following:

(1) The area corresponding to the main tourist attractions of the city (Cathedral's square) is the one that concentrates the largest number of arches with high WCI: this is due not only to the presence of local amenities, but also to the pedestrianization of most of the infrastructures and the proximity to the port entrance.

(2) Streets located in the south-west of the port have a worse 
WCI: those coincide with an area of degradation in the urban area of the city which, despite some redevelopment attempts, has not yet managed to improve its attractiveness;

(3) Other paths with low WCI are located in the northern part of the study area: they are also part of a degraded district of the city (San Berillo District), which in the last few years is experiencing an era of extensive redevelopment, with the birth of new commercial activities and local associations that work there energetically.

\subsubsection{Example of policy implication: identification of routing} scenarios and best path solutions

This section describes an example of application of use of the WCI in a multilayer GIS environment, in order to identify areas with a bad quality of pedestrian facility and prioritize interventions on it. The application, always related to the case study of the port of Catania, deals with the organization of a touristic itinerary from the port to the following six places of historic interest: Cathedral's square, Ursino Castle, Teatro Massimo square, San Berillo District, Crociferi Street (Figure $7 \mathrm{a})$. ORS tool has been used to evaluate the fastest routing to reach the 5 places starting from the port, and coming back to it, such as in an itinerary that could be put in place by a cruiser in a relatively short time (Figure 7a).

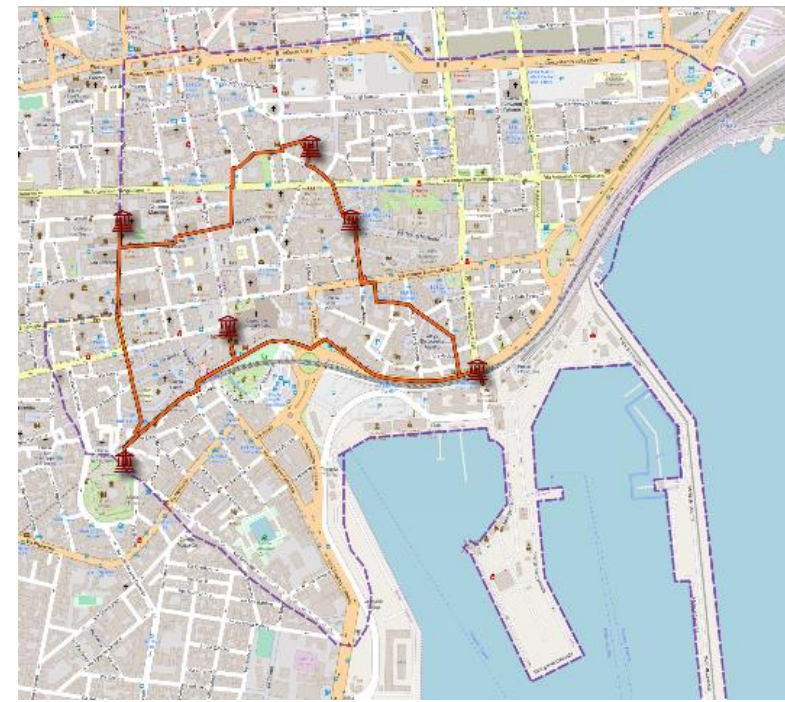

(a) Fastest pedestrian route to selected points of interested

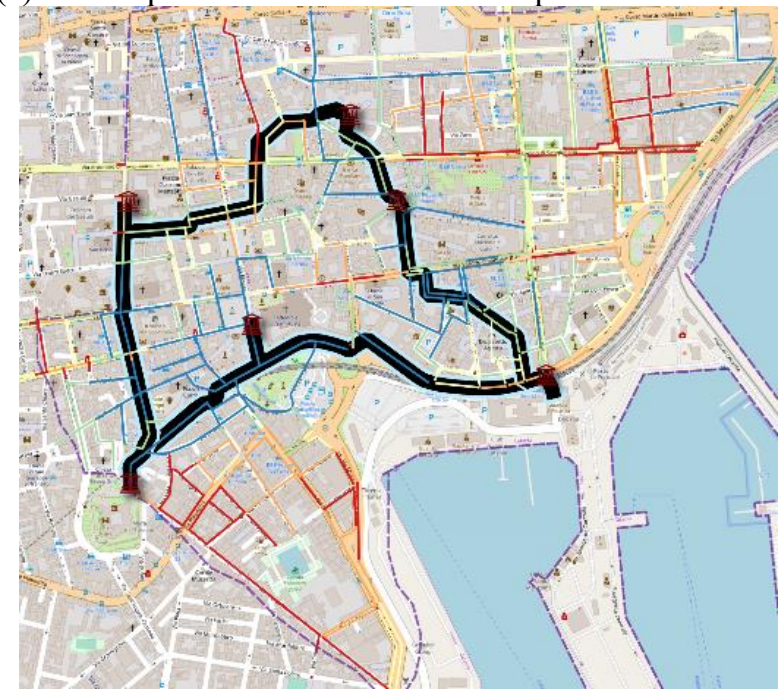

(b) WCI for the route's arcs and areas with lower WCI

Figure 7. Faster path resulting from routing procedure. Source: own elaboration
On the basis of the routing procedure carried out by the software, the path obtained presents overall good pedestrian quality (Figure 7b); the areas with the lowest WCI values correspond to: (i) the path near the port access (Figure 8a), which does not have an adequate pedestrian infrastructure on both sides of the roadway and is influenced by high traffic flows; (ii) a zone in the north of the study area (Figure 8b) which is characterized by narrow streets with undersized sidewalks and poor quality of the attractiveness of the surrounding environment also due to the land use reserved for parking.

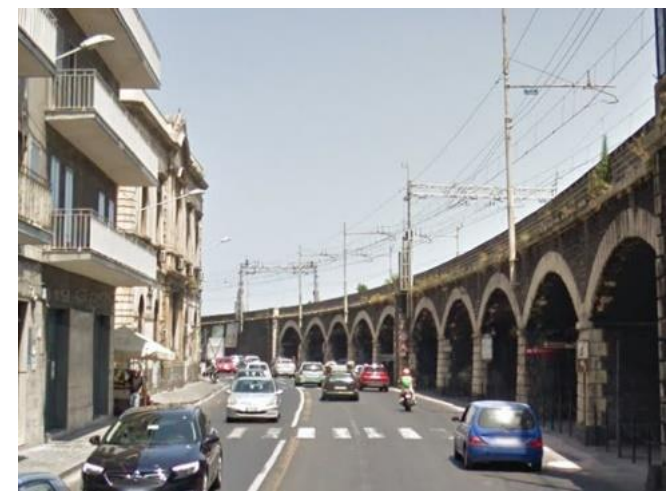

(a) Fastest pedestrian route to selected points of interested

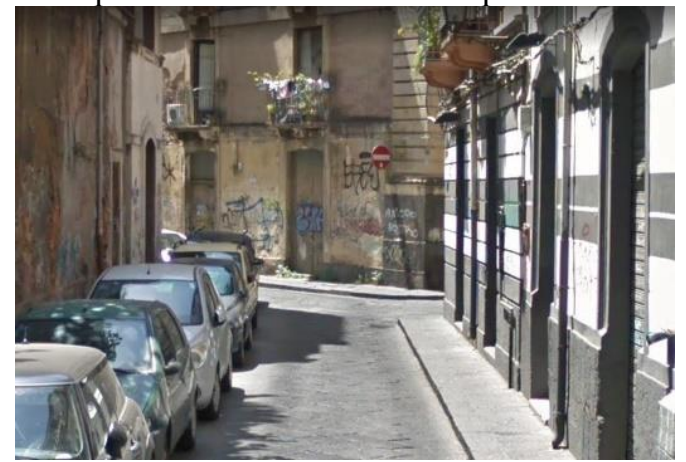

(b) comprehensive score for the route's arcs

Figure 8. Examples of streets with the lowest WCI. Source: own elaboration

Results show that this type of analysis can be an aid to decision makers not only to easy identify the main paths on which to intervene to improve their quality, but also to understand which of the various of the three components it is necessary to intervene on.

\section{CONCLUSIONS}

The development of the commercial areas of the ports that has characterized the last few years has led to a mixture of the use of the territory in the port cities which has often made some routes tangent to the main areas of interest of the city unattractive for pedestrians and in general for the nonmotorized traffic. Actually, given the recent growth of cruise traffic in the Mediterranean and in general of passenger seatraffic, it is necessary to ensure that these flows are not only an environmental and economic burden for the areas in which ships stop, but also a further opportunity to economic income and redevelopment of degraded areas of the city.

In this view, this study developed a comprehensive index, the WCI, to assess non-motorized paths of access to city areas from the port; the WCI includes a PLOS evaluation according 
to HCM standards, a component related to accessibility in terms of time and the evaluation of attractiveness, based on the number of activities/opportunities that could be easily reached by pedestrian, evaluated through an open source spatial approach. The use of open source constitutes a significant saving in conducting a spatial analysis that must take into consideration a large amount of data on the activities present on the territory; it also ensures a faster update for future evaluations. Data included in the analysis of the attractiveness component and the constant update of point of interest present in the accessibility evaluation are the key points that could limit the quality of the provided approach. The current limitation of the WCI could be overcome by introducing new information for these two components. The availability of new data is indeed the basis for future research developments and improvement of the index evaluation: building context, degraded urban landscape, presence of green areas, traffic flows but also pedestrian demand patterns could be added to the spatial model in order to better identify paths with priority of intervention.

\section{ACKNOWLEDGEMENTS}

The work has been partially financed by the project "THALASSA - Technology and materials for safe low consumption and low life cycle cost vessels and crafts" (unique project code CUP B46C18000720005) under the programme "PON Ricerca e Innovazione 2014 - 2020".

\section{REFERENCES}

[1] Ignaccolo M., Caprì S. (2000). Pedestrian accessibility and mobility within the island of Ortigia, Siracusa. Conference proceeding of the VII International Conference "Living and Walking in Cities", Brescia.

[2] Giuffrida, N., Ignaccolo, M., Inturri, G., Rofè, Y., Calabrò, G. (2017). Investigating the correlation between transportation social need and accessibility: The case of Catania. Transportation Research Procedia, 27: 816-823. http://dx.doi.org/10.1016/j.trpro.2017.12.122

[3] Giuffrida, N., Inturri, G., Spica, S., Ignaccolo, M. (2017). The impact of a bus rapid transit line on spatial accessibility and transport equity: the case of Catania. Proceedings of the AIIT International Congress on Transport Infrastructure and Systems, Rome, Italy, pp. 753-758. http://dx.doi.org/10.1201/9781315281896-97

[4] Cocuzza, E. (2017). Sostenibilità dei sistemi portuali in ambito urbano. Valutazione dell'accessibilità non motorizzata nelle aree di interfaccia porto/città. $\mathrm{PhD}$ Thesis, University of Catania. http://dspace.unict.it/handle/10761/3812, accessed on May 20, 2019.

[5] Hahm, Y., Yoon, H., Choi, Y. (2019). The effect of built environments on the walking and shopping behaviors of pedestrians; A study with GPS experiment in Sinchon retail district in Seoul, South Korea. Cities, 89: 1-13. http://dx.doi.org/10.1016/j.cities.2019.01.020

[6] Hansen, W.G. (1959). How accessibility shapes land use. Journal of the American Planning Institute, 25(2): 73-76. http://dx.doi.org/10.1080/01944365908978307

[7] Dalvi, M.Q., Martin, K.M. (1976). The measurement of accessibility: Some preliminary results. Transportation, 5(1): 17-42. http://dx.doi.org/10.1007/BF00165245

[8] Ben-Akiva, M.E., Lerman, S.R. (1979). Disaggregate travel and mobility-choice models and measures of accessibility. Behavioural Travel Modelling, edited by Hensher, D.A., Storper, P.R., London, 654-79. https://scholar.google.com/scholar?cluster $=4780375191$ 991714450\&hl=it\&as_sdt $=0,5$.

[9] Wang, Y.H., Cullinane, K. (2008). Measuring container port accessibility: An application of the principal eigenvector method (PEM). Maritime Economics \& Logistics, $\quad 10$ : 75-89. http://dx.doi.org/10.1057/palgrave.mel.9100192

[10] Iacono, M., Krizek, K., El-Geneidy, A. (2010). Measuring non-motorized accessibility: Issues, alternatives, and execution. Journal of Transport Geography, 18(1): 133-140. http://dx.doi.org/10.1016/j.jtrangeo.2009.02.002

[11] Gould, E. (2011). Applying international best practice: measuring and improving the performance of pedestrian environments. Annual Conference of the Transportation Association of Canada Edmonton, Alberta.

[12] Transportation Research Board of the National Academies (2010). Highway Capacity Manual 2010. Washington DC.

[13] Owen, N., Humpel, N., Leslie, E., Bauman, A., Sallis, J.F. (2004). Understanding environmental influences on walking: Review and research agenda. American Journal of Preventive Medicine, 27(1): 67-76. https://doi.org/10.1016/j.amepre.2004.03.006

[14] Southworth, M. (2005). Designing the walkable city. Journal of Urban Planning and Development, 131(4): 246-257. http://dx.doi.org/10.1061/(ASCE)07339488(2005)131:4(246)

[15] D’Orso, G., Migliore, M. (2018). A GIS-Based Method to Assess the Pedestrian Accessibility to the Railway Stations. In: Gervasi O. et al. (eds) Computational Science and Its Applications - ICCSA 2018. ICCSA 2018. Lecture Notes in Computer Science, vol 10964. Springer, Cham. https://doi.org/10.1007/978-3-31995174-4_2

[16] Ignaccolo, M., Inturri, G., Giuffrida, N., Cocuzza, E., Torrisi, E. (2019). Framework for the evaluation of the quality of pedestrian routes for the sustainability of portcity shared areas. WIT Transactions on The Built Environment, 188: 11-22. http://dx.doi.org/10.2495/CC190021

[17] Port System Authority of the Eastern Sicilian Sea (2018). Traffici Portuali 2018 Porto di Catania. Accessed on the 05/01/2020 https://www.adspmaresiciliaorientale.it/wpcontent/uploads/2019/04/Traffici-portuali-2018-Portodi-Catania-1.pdf.

[18] Ignaccolo, M., Inturri, G., Giuffrida, N., Torrisi, V., Cocuzza, E. (2020). Sustainability of freight transport through an integrated approach: The case of the eastern Sicily port system. Transportation Research Procedia, 45: 177-184. http://dx.doi.org/10.1016/j.trpro.2020.03.005

[19] Giuffrida, N., Le Pira, M., Inturri, G., Ignaccolo, M. (2019). Mapping with stakeholders: An overview of public participatory GIS and VGI in transport decisionmaking. ISPRS International Journal of Geo-Information, 8(4): 198. http://dx.doi.org/10.3390/ijgi8040198 